\title{
Experience of Managing Urogenital Fistula
}

\author{
Pradhan HK, Dangal G, Karki A, Shrestha R, Bhattachan K
}

Department of Obstetrics and Gynaecology, Kathmandu Model Hospital, Exhibition Road, Kathmandu.

\begin{abstract}
Aim: The study was done to review the demography of urogenital fistulae including obstetric fistula (OF) and its surgical outcome in the early phase of fistula surgery and to create awareness about OF.
\end{abstract}

Methods: This was a retrospective study of 47 patients who underwent fistula surgery during the period of January 2012 to May 2014 in Kathmandu Model Hospital, Helping Hand Community Hospital, Camp in Mid-wetern Regional Hospital Surkhet and Hamlin Hospital, Ethiopia. The primary outcome was in terms of urinary continence after 14 days of repair.

Results: In the study $70 \%(n=33)$ of fistula were due to obstructed labour and 30\% $(n=14)$ were due to hysterectomy for gynecological indications. Ninety six percent $(n=45)$ had successful closure of fistula. Seventy seven percent $(n=36)$ were continent after surgery, and $17 \%(\mathrm{n}=8)$ had some stress incontinence.

Conclusions: The study showed obstructed labour was the major cause of OF, however iatrogenic fistula was also becoming common. The success of repair depended on the type, site, size of fistula and urethral length. Majority of our cases had successful closure of fistula with some degree of stress in some patients.

Keywords: fistula repair, obstructed labour, obstetric fistula, vesicovaginal fistula.

\section{INTRODUCTION}

Genital fistula is a tragedy of developing world because of illiteracy, poverty, ignorance and lack of health facilities. Obstetric fistula is an abnormal hole between the vagina and the urinary bladder (VVF) or vagina and rectum (RVF) resulting in urinary incontinence or fecal incontinence caused by unrelieved obstructed labor. Prolonged pressure of the baby's head against the back of the pubic bone produces ischemic necrosis of the intervening soft tissue. The extent of injury depends on the duration of labor. In most severe cases, ischemia affects the whole of anterior wall of vagina, bladder base, much of urethra and sometimes the rectum. ${ }^{1}$

\section{CORRESPONDENCE}

Dr Hema Kumari Pradhan

Department of Obstetrics and Gynaecolgy,

Kathmandu Model Hospital, Exhibition Road, Kathmandu,

Nepal.

Email: drhemapradhan@hotmail.com

Phone: +977-9849375252
Obstetric fistula is a disease of developing world whereas in developed world it occurs after hysterectomy and other gynaecological surgeries. It is estimated that there are at least two million women living with fistula primarily in sub- Sahara Africa and South Asia and some 50,000-100,000 women are affected each year. ${ }^{2,3}$ The women who survive with OF suffer from devastating conditions like damaged cervix, neurological condition like foot drop, leakage of urine and/ or faeces, ammonical dermatitis, social isolation and they are abandoned by family and husband. Women suffer for years as treatment services are rare and even when available they lack the knowledge that fistula can be repaired and or they lack resources for treatment. ${ }^{3}$ Thousands of Nepalese women silently suffer from OF. It is estimated that 200- 400 new cases of OF occur each year in Nepal. ${ }^{4}$

\section{METHODS}

This study was conducted from January 2012 to May 2014 in Kathmandu Model Hospital, OF fistula camp in Surkhet in Mid-western Regional Hospital, 
Helping Hand Community Hospital and Hamlin Fistula Hospital Ethiopia. Only the patients operated by the authors were included in the study. Permission was obtained from institutional ethical committees. Operation records of the patients were analyzed. All the patients were admitted two to five days prior to surgery. Routine pre-operative investigations such as complete blood count, blood biochemistry, viral markers and chest $\mathrm{x}$-ray and ECG where indicated were done. Urine samples were obtained for culture sensitivity and antibiotic treatment was given accordingly. Ultrasonography of abdomen and pelvis was done when indicated. Goh system of classification of fistula depending on the site and size of fistula,urethral length and scarring was followed. ${ }^{1}$

The operations were done under spinal anesthesia in case of vaginal route and general anesthesia in case of abdominal route. The basic principles of fistula repair such as adequate exposure, protection of ureters, mobilization of enough bladder after excision of scar to allow tension free closure, support for the urethra where deficient, and dye test at the end of operation were followed. The fistulae were closed in one layer with interrupted suture. Postoperative continuous catheter drainage was done for 14 days. The ureteric catheters were kept for 3-7 days. The 3D principle (dry, drinking and draining) was followed. On $14^{\text {th }}$ day in dry patients, methylene blue dye test was done before removal of catheter. After removal of catheter patients were advised to drink plenty of water and void frequently. They were discharged 24 hours after removal of catheter. Surgery was considered successful if there was no leakage of urine and patient can hold urine.

\section{RESULTS}

Forty-seven patients were included in the study. Twenty-eight patients were from Hamlin Hospital, 9 were from Kathmandu Model Hospital, 9 from Surkhet Mid -Western Regional Hospital, 1 from Helping Hands Community Hospital.

The demography of the patients including age, parity and birth status is shown in Table1.
Table 1. Demographic and obstetric characteristics of women with fistula $(n=47)$.

\begin{tabular}{lr}
\hline Variable & Number $(\%)$ \\
\hline Age (years) & $2(4 \%)$ \\
$>20$ & $22(47 \%)$ \\
$20-29$ & $12(26 \%)$ \\
$30-39$ & $7(15 \%)$ \\
$40-49$ & $3(6 \%)$ \\
$50-59$ & $1(2 \%)$ \\
60 above & \\
Parity & $15(32 \%)$ \\
1 birth & $11(23 \%)$ \\
2 births & $21(45 \%)$ \\
3 births or more & \\
Birth Status & $38(81 \%)$ \\
Still birth & $9(19 \%)$ \\
\hline Live birth
\end{tabular}

The age ranged from 18- 60 years with the median age of 29. The highest parity was seven, 38 had no living issue of which 23 were multipara and 15 were primi para. Remaining 9 patients had living issue.

Patient distribution according to Goh's classification is shown in Table 2.

Table 2. Patient distribution according to Goh's classification $(n=47)$.

\begin{tabular}{lr}
\hline Goh's class & Number \\
\hline $1 \mathrm{aI}$ & 5 \\
$1 \mathrm{aII}$ & 7 \\
$1 \mathrm{aIII}$ & 2 \\
\hline $1 \mathrm{bI}$ & 1 \\
$1 \mathrm{bII}$ & 4 \\
$1 \mathrm{bIII}$ & 3 \\
$2 \mathrm{aIII}$ & 1 \\
$2 \mathrm{bI}$ & 3 \\
$2 \mathrm{bII}$ & 2 \\
\hline $2 \mathrm{bIII}$ & 1 \\
$2 \mathrm{cI}$ & 1 \\
$2 \mathrm{cIII}$ & 1 \\
$3 \mathrm{aII}$ & 1 \\
$3 \mathrm{bI}$ & 1 \\
$3 \mathrm{bII}$ & 4 \\
$3 \mathrm{bIII}$ & 1 \\
$3 \mathrm{cI}$ & 1 \\
$3 \mathrm{cII}$ & 2 \\
$3 \mathrm{cIII}$ & 3 \\
$4 \mathrm{cII}$ & 1 \\
$4 \mathrm{bIII}$ & 1 \\
$4 \mathrm{cIII}$ & 1 \\
\hline
\end{tabular}


Site, size and scarring were taken into consideration

Most of the fisula was simple and easier to repair. However, the outcome of repair mostly depended on the higher grade of severity in the classification.

Out of 47 patients two were operated from abdominal route due to inaccessibility from vaginal route. In two patients with VVF and RVF combined, successful repair of RVF was done and VVF repair was postponed. One patient leaked on third postperative day that was again repaired on the same day. There were three cases of broken VVF and one case of recurrent VVF that were operated before for OF. One patient with Goh 4CIII had fat graft. One patient developed right ureteric fistula after 20 days of total laparoscopic hysterectomy for fibroid uterus. Cystoscopy and ureteric stenting was done for it. In 38 cases bilateral ureteric catheters were kept and six cases did not need ureteric catheter.

Regarding the causes of fistula, majority i.e. $70 \%$ $(\mathrm{n}=33)$ had obstetrical cause and the remaining 30\% $(n=14)$ had gynecological cause (Table 3$)$.

Table 3. Causes of fistula $(n=47)$.

\begin{tabular}{lr}
\hline Causes & Number \\
\hline Obstetrical cause & \\
After caesarean hysterectomy & 6 \\
After ceasarean section & 10 \\
for obstructed labour & 2 \\
After instrumental delivery & 15 \\
After prolonged and difficult & \\
vaginal delivery & 14 \\
\hline Gynaecological causes & \\
\hline
\end{tabular}

\section{DISCUSSION}

In our series $70 \%(\mathrm{n}=33)$ cases of fistula were due to obstructed labour and $30 \%(\mathrm{n}=14)$ were from hysterectomy for gynecological causes as compared to $95.6 \%$ due to Obstructed labour and $4.4 \%$ due to gynecological causes in the study done in Eastern Nepal. ${ }^{5}$ This is due to the difference in study place as in our series in Kathmandu Model hospital there were more cases of post-hysterectomy fistula due to gynecological causes. In $32 \%(n=15)$ it developed after first child birth which is comparable to $39 \%$ in study from Eastern $\mathrm{Nepal}^{5}$ and $45.8 \%$ from a Nigerian study. ${ }^{6}$
There were only two patients below 20 years of age. As in study from Eastern Nepal, ${ }^{5}$ teenage pregnancy was not common in our study too. Twenty one percent $(n=10)$ developed fistula after emergency caesarean section which is comparable to $26 \%$ in study from Eastern Nepal, ${ }^{5}$ and $19 \%$ in one study from India. ${ }^{7}$ Four percent $(\mathrm{n}=2)$ developed OF after instrumental delivery. This scenerio indicates that women seek medical rescue only after a prolonged obstructed labour where $\mathrm{OF}$ is inevitable.

In our series fistula was closed in $96 \%(\mathrm{n}=45)$ and $77 \%(\mathrm{n}=36)$ were continent at discharge as compared to $76 \%$ in a study from India ${ }^{7}$ and $17 \%(n=8)$ had stress incontinence as compared to $87 \%$ closed fistula, $76 \%$ continent and $23 \%$ incontinent in study from Burundy. ${ }^{8}$ The success of fistula repair varies in literature from $61-95 \%$ as the result vary with the type, size and location, whether the repair is the first attempt or a subsequent effort, the presence of a combined RVF or ureterovaginal fistula. ${ }^{9-11}$ In our study there were more anatomically simple type of fistula (Table 2) which increased the success rate. Approximately $80 \%$ of women with obstetric fistula never seek treatment due to lack of awareness, affordability or access. Even those who are able to seek treatment have to travel long distances to repair centres and wait for weeks to get repaired due to various constraints like a heavy backlog of cases, few surgeons, shortage of supplies and equipment among others. ${ }^{12-16}$

\section{CONCLUSIONS}

The study showed obstructed labour was the major cause of fistula. The success depended on the type, site, size and scarring of fistula. Majority of our cases had successful closure of fistula with some degree of stress in some patients. To fight the problem essential obstetric care service including preventive strategies for OF should be available in every part of the country.

\section{DISCLOSURE}

The authors report no conflicts of interest in this work.

No violation of human rights and safety.

Funding: Nil 


\section{REFERENCES}

1. Hancock B, Browning A. Practical Obstetric Fistula Surgery.1st ed. London: Royal Society of Medicine Press Limited; 2009.

2. Lewis G, de Bernis L, editors. Obstetric fistula: guiding principles for clinical management and programme development. Geneva: World Health Organization; 2006.

3. Miller S, Lister F, Webster M, Cowan B. Obstetric fistula: a preventable tragedy. J Midwifery Womens Health. 2005; July-Aug; 50(4): 286-94.

4. Tebeu PM, Upadhyay M. Campaign to end fistula in Nepal: need assessment for obstetric fistula in Nepal. Kathmandu: UNFPA; 2011.

5. Upreti DK, Subedi S, Budhathoki B, Regmi MC. Vesicovaginal fistula at tertiary care centre in Eastern Nepal. J Nepal Med Assoc. 2008;47(171):120-2.

6. Wall LL, Karshima JA, Kirschner C, Arrowsmith SD. The obstetric vesicovaginal fistula: characteristics of 899 patients from Jos, Nigeria. AJOG. 2004; 190:1011-9.

7. Mathur R, Joshi N, Aggarwal G, Raikwar R, Shrivastava V, Mathur P,et.al., Urogenital fistulae: A prospective study of 50 cases at a tertiary care hospital. Urol Ann. 2010 MayAug; 2(2): 67-70.

8. Smith KT, Zacharich R, Manzi M, van den Boogaard $\mathrm{W}$, Vandeborne A, Bishigna A, etal. Obstetric fistula in Burundi: a comprehensive approach to managing women with this neglected disease. BMC Pregnancy and childbirth. 2013;13:164.

9. Elkins TE. Surgery for the obstetric vesicovaginal fistula: a review of 100 operations in 82 patients. Am J Obst Gynecol. 1994; 170:1108-20.

10. Ama MR. Vesicovaginal fistula in Jourdan. Eur J Obstet Gynecol Reprod Biol. 1998; 80(2):201-3.

11. Hiltan P, Ward A. Epidemiological and surgical aspect of urtogenital fistulae: a review of 25 years' experience in southeast Nigeria. Int Urogynecol J Pelvic Floor Dysfunction. 1998;9(4):189-94.

12. UNFPA and Engender Health. Obstetric fistula needs assessment report: findings from nine African countries. New York: UNFPA and Engender Health; 2003.

13. UNFPA and Ministry of Health Uganda. Campaign to end fistula: baseline assessment of obstetric fistula in Uganda. New York: UNFPA; 2003.

14. Kelly J. An epidemiological study of vesicovaginal fistula in Addis Ababa. World health statistics quarterly report. 1995,48(1):15-7.

15. Upreti D, Babu S, Sharma M, Jha M. Obstetric urogenital fistula in eastern part of Nepal. Asian Journal of Obstetrician and Gynecology Practice. 2002;6(1):35-8.

16. Dangal G, Thapa K, Yangzom K, Karki A. Obstetric fistula in the developing world: an agonizing tragedy. NJOG. 2013;8(2):5-15. 